\title{
Covid 19 Vaccine - boon or a bane?
}

\section{Kasturi Ravinder Reddy ${ }^{1}$, Samkisha Earna ${ }^{2}$}

1. Consultant Cardiologist and Head of the department,General medicine,Prathima institute of medical sciences,karimnagar

2. Post graduate 2nd year, General Medicine, Prathima Institute of Medical Sciences

Corresponding author : Dr.K.Ravinder reddy, Consultant Cardiologist and Head of the department, General medicine, Prathima institute of medical sciences, karimnagar.

DOI : 10.47799/pimr.0802.02

The global struggle against corona virus disease 2019(COVID19) is now in its 8th month since the pandemic virus SARS -COV2 has first emerged.The severe economic,personal and psychological adverse effects of shutdowns and social distancing make these effective preventive measures challenging to sustain long term.Safe and effective COVID-19 vaccine could lead to a level of global immunity that stops the pandemic.This is the anti COVID-19 intervention most public health leaders and many people long for the most.

As of August 2020,there were 231 vaccine candidatesin development although no vaccine has completed clinical trials to prove its safety and efficacy. ${ }^{1}$

26 vaccine candidates are in clinical trials with 20 still in phase I-II and 6 beginning phase III 2 among which three are Chinese COVID-19 vaccines (inactivated virus based) from Sinovac/Institute Butantan, Wuhan institute of biological products/sinopharm and beijing institute of biological products/sinopharm, the other three leading candidates are developed by oxford/astrazeneca(modified adenovirus vector), moderna/NIAID(mRNA based) and Bio-N tech/Fosun pharma/Pfizer (mRNA based)

WHO however warned "entering phase III doesn't mean nearly there" as there is no guarantee that any of these six will give us the answer.

Sputnik 5 Russian based COVID-19 vaccine (adeno based) is a medical coup,a propaganda coup,a political and marketing coup.Phase I/II trials are inadequate to prove it's efficacy and safety because of three reasons 1 ) it was tested only on 76 people ${ }^{2}$ it is a two dose vaccine but in phase $\mathrm{I} / \mathrm{II}$ only one dose was given 'it's phase I/II results were not published therefore not peer reviewed. ${ }^{3}$

India based Bharath biotech(inactivated virus based)/ zydus cadila( DNA based) vaccine trials demonstrated an encouraging safety profile in phase I and moved to phase II.

\section{Limitations of COVID-19 vaccine}

- Host related determinants such as genetics, health status,immunocompetence, age,economic and cultural environment can affect the severity of infection and response to vaccine. ${ }^{4}$
- Elderly,allergen hypersensitive,obese may require separate vaccine technology or repetitive booster vaccinations. ${ }^{4}$

- Sometimes vaccine may have unintended opposite effect by having antibody dependent disease enhancement. ${ }^{5}$

- Further mutation of virus altering it's structure can make vaccine ineffective. ${ }^{6}$

\section{CONCLUSION:}

" may be sometimes it's riskier not to take a risk" -Danny wallace

Inspite of the limitations, benefits overweigh risks. Hoping for the phase III vaccines to complete it's trial successfully and launching the vaccine against COVID-19 to end this pandemic soon.

\section{REFERENCES}

1. MILKEN INSTITUTE. COVID-19 vaccine tracker- Milken Institute. 23 June 2020.

2. WORLD HEALTH ORGANISATION. Draft landscape of COVID 19 candidate vaccines". World Health Organization. 21 July 2020

3. Kate kelland.Scientists ask: Without trial data, how can we trust Russia's COVID vaccine?". Reuters. Retrieved 11 August 2020.

4. Wiedermann U,Garner-Spitzer E,Wagner A.Primary vaccine failure to routine vaccines: Why and what to do?". Human Vaccines and Immunotherapeutics,2016. 12 (1): 239-43.

5. Iwasaki A,Yang Y.The potential danger of suboptimal antibody responses in COVID-19. Nature Reviews Immunology,21 April 2020.20 (6): 339-41.

6. Zumla A,Hui DS,Perlman S.Middle East respiratory syndrome". Lancet,11 September 2015.386 (9997).

How to cite this article : Kasturi RR, Earna S. Covid 19 Vaccine - boon or a bane?. Perspectives in Medical Research 2020; 8 (2):3 DOI : 10.47799/pimr.0802.02

Sources of Support: Nil, Conflict of interest: None declared 